\title{
Bacteriological Profile and Antimicrobial Susceptibility Patterns of Bacteria Isolated from various Culture Samples of Patients Attending RDBP Jaipuriya Hospital, Jaipur
}

\author{
Bhagwati Chundawat $^{1 *}$, Manuja Agarwal ${ }^{2}$, Nilofer Khayyam $^{1}$, Gaurav Dalela ${ }^{1}$, \\ Ekadeshi Sabhrawal $^{1}$ and Vijeta Sharma ${ }^{1}$
}

\author{
${ }^{1}$ Department of Microbiology, Rajasthan University of Health Sciences-College of Medical \\ Science, India \\ ${ }^{2}$ Microbiology Dpt RDBP Jaipuriya, India \\ *Corresponding author
}

\section{Keywords \\ Pathogenic \\ Organism, \\ Antimicrobial \\ Sensitivity Pattern, \\ MRSA, ESBL \\ Article Info \\ Accepted: \\ 07 May 2019 \\ Available Online: \\ 10 June 2019}

A B S T R A C T

Bacterial infections are most commonly encountered by clinicians in developing countries. Area-specific monitoring studies done to assess the type of pathogens and their antibiotic sensitivity patterns which help the clinician to opt for best empirical treatment. The hospital based cross sectional study is conducted on various samples collected using sterile techniques from 2474 clinically-suspected cases attending RDBP, Jaipuriya Hospital from Jan 2016 to Dec 2017 and tested bacteriologically using standard conventional procedures. Antimicrobial susceptibility test was performed for the isolated pathogens using KirbyBauer disk diffusion method according to Clinical and Laboratory Standards Institute guidelines. Total of 2474 culture samples collected were cultured using standard microbiological techniques. The colonies grown were identified with the help of gram staining and biochemical tests. The antimicrobial susceptibility testing was performed by Kirby-Bauer disc diffusion technique. Out of 2474/ 680 were positive. Gram positive bacteria were isolated 252/680 samples and Gram-negative bacteria were found in 404/680 samples. Coagulase negative Staphylococcus aureus 108/252 was the predominant in Gram-positive bacteria isolated and Escherichia coli 255/404 were predominant in Gram negative bacteria. Primary screening of Methicillin-resistant Staphylococcus aureus (MRSA) isolates were detected by using cefoxitin disc $(30 \mu \mathrm{g})$ is $43.47 \%$ and Extended spectrum $\beta$ lactamase (ESBL) detection done by the difference of Ceftazidime and Ceftazidime Clavulunate difference is more than $5 \mathrm{~mm}$ is $52.35 \%$. The Vancomycin resistant Enterococci (VRE) detection is $21.77 \%$. Antibiotic sensitivity of gram positive bacteria is Linezolid $90.47 \%$, Vancomycin $77.77 \%$, Doxycycline $60 \%$ and cefoxitin $45 \%$. Antibiotic sensitivity of gram negative bacteria is Imipenam 87.6\%, Gentamicin 47\%, Ceftazidime Clavulunate $60 \%$. This study showed that E. coli and Coagulase Negative Staphylococci isolates were the predominant pathogens. Sensitivity of Linezolid, Vancomycin, Doxycyline, Imipenam, Gentamicin, Ceftazidime clavulunate is seen in the bacterial strain found in the Jaipuriya setting. Since drug resistance is an evolving process, routine surveillance and monitoring studies should be conducted to provide physicians the updated and most effective empirical treatment. 


\section{Introduction}

Bacterial Infections is a major public health problem and causes complications and sometimes leads to fatal septicemia especially in the presence of various precipitating factors like reduce immune system, altered function of organ, burns, and road traffic accidents. Antibiotic resistance is a serious problem that has the potential to drag the world into preantibiotic era (1)

The most common cause of this is the irrational use of antibiotics by the people and doctors. Over $95 \%$ of all deaths occur in developing and under developing countries (2).

The common bacterial pathogens responsible for infections are Coagulase Negative Staphylococci, Staphylococcus aureus, Enterobacteriaceae and Pseudomonas aeruginosa (3). There are reports of increasing rate of infection by MRSA, ESBL and VRE as the common cause of nosocomial and community acquired infections (4). Many studies have been conducted to determine the rates of infections caused by MRSA among adults (6). If the local antimicrobial susceptibility data are not available, the chances of haphazard use of antibiotics will be high.

As a result, the rate of drug resistance will increase causing a serious problem. So, in this study, we determined to produce the bacteriological profile in various samples in the population and their antimicrobial susceptibility patterns, as for patients prone to serious infections and for their timely treatment is very necessary.

To find out the bacteriological pattern existing at the RDBP Jaipuriya hospital and the antibiotic sensitivity pattern of these pathogens. To improve the antibiotic policy of the setting, to prevent misuse of antibiotics and prevent development of the resistant strains of pathogen.

The assessment of the type of the bacterial pathogen most commonly affecting the population

Find the antibiotic sensitivity pattern for the pathogens

\section{Materials and Methods}

\section{Study design}

A hospital based cross-sectional study was conducted using total of 2474 culture samples collected from the patients attending, RDBP Jaipuriya Hospital, Jaipur, from Jan 2016 to Dec 2017 who came to the OPD and were admitted to the hospital.

\section{Isolation, identification, and antimicrobial} susceptibility testing

The samples were subjected to bacteriological culture following standard conventional microbiological techniques (7). The colonies grown were identified with the help of colony morphology, Gram's staining, and biochemical tests (8). The antimicrobial susceptibility testing was performed by modified Kirby-Bauer disc diffusion technique following clinical and laboratory standards institute guidelines (9).

\section{Primary detection of MRSA, ESBL, VRE} strains

Methicillin Resistant Staphylococci aures isolates were detected by using cefoxitin disc (30 $\mu \mathrm{g})$ sensitivity pattern in MHA (9) Extended spectrum $\beta$ lactamase strain were detected by noting the zone difference $b / w$ Ceftazidime and Ceftazidime clavulunate more than $5 \mathrm{~mm}$. Vancomycin Resistance Enterococci is seen by noting Vancomycin resistance in Enterococci antibiotic pattern. 


\section{Quality control}

For quality control, S. aureus (ATCC 25923) and $E$. coli (ATCC 25922) were used.

\section{Data analysis}

The data were analyzed by using statistical package for the social sciences version 16.00. $P$ value $<0.05$ was considered as statistically significant.

\section{Results and Discussion}

\section{Profile of culture samples}

Total of 2474/680 positive, Urine culture 2040/500 positive and others were sputum, pus, throat culture, tissue, body fluid sample are 434/180 Samples obtained from both OPD 1973/2474 (79.7\%) and IPD 501/2474(20.25)

\section{Bacteriological Profile of culture samples}

Out of 680 growth positive samples, Grampositive bacteria were isolated from 252 /680(37.05) samples and Gram-negative bacteria were found in $404 / 680$ (59.41) samples. Among Gram-positive isolates, 108/252 (42.85\%) were Coagulase negative staphylococcus and 86/252 (34.12\%) were Staphylococcus aureus others are streptococci, enterococci. Similarly, among Gram-negative isolates, the most prevalent bacteria isolated were Escherichia coli, 255/404(62\%) followed by Klebsiella pneumoniae, 71/404 (17.57\%) other organism detected is Acinetobacter spp, Citrobacterspp, Proteus mirabilis Candida is also isolated pathogen (Table 1).

Antibiotic susceptibility patterns of S. aureus

Highest rate of susceptibility was seen toward linezolid $(90.47 \%)$ followed by vancomycin $(77.77 \%)$ and doxycycline (60\%) (Table 2). Isolates that were resistant to cefoxitin, screened as methicillin-resistant $\mathrm{S}$. aureus is $43.47 \%$ done by seeing the resistance of cefoxitin $40 \mu \mathrm{g}$ in Muller Hinton Agar. Vancomycin resistant enterococci isolates are $21.77 \%$ seen by noting the resistance of vancomycin (Table 3 ).

Table.1 Bacteriological profile of pathogen isolated

\begin{tabular}{|l|c|}
\hline Total Gram negative organism & $\mathbf{4 0 4}$ \\
\hline Escherichia Coli & $\mathbf{2 5 5}$ \\
\hline Klebsiella & 71 \\
\hline Proteus & 14 \\
\hline Enterobacter spp & 27 \\
\hline Citrobacter spp & 7 \\
\hline Acinetobacter spp & 5 \\
\hline Pseudomonas Spp & 25 \\
\hline total gram Positive organism & $\mathbf{2 5 2}$ \\
\hline Coagulase Negative Staphylococci & $\mathbf{1 0 8}$ \\
\hline Staphylococcus aureus & 86 \\
\hline Streptococcus & 15 \\
\hline Enterococcus & 43 \\
\hline Candida & 24 \\
\hline
\end{tabular}


Table.2 Antibiotic sensitivity pattern of bacteria isolated

\begin{tabular}{|c|c|}
\hline $\begin{array}{l}\text { Antibiotic sensitivity for gram positive } \\
\text { organism }\end{array}$ & $\begin{array}{c}\text { percentage of sensitivity for } \\
\text { GPC }\end{array}$ \\
\hline Linezolid & 90.47 \\
\hline Vancomycin & 77.77 \\
\hline Doxycycline & 60 \\
\hline Cefoxitin & 45 \\
\hline $\begin{array}{l}\text { Antibiotic sensitivity for gram negative } \\
\text { organism }\end{array}$ & $\begin{array}{l}\text { percentage of sensitivity for } \\
\text { GNB }\end{array}$ \\
\hline Imepenam & 87.6 \\
\hline Gentamicin & 47 \\
\hline ceftazidime clavulunate & 60 \\
\hline
\end{tabular}

Table.3 Superbug isolated from the hospital setting

Extended Spectrum beta lactamase ESBL organism \% in GNB Methicillin Resistant Staphylococci aureus MRSA organism \% in GPC

Vancomycin resistant Enterococci VRE \% in GPC

$52.35 \%$

$43.47 \%$

$21.77 \%$

Table.4 Comparison of my study with other studies in case of organism isolation

\begin{tabular}{|l|r|l|r|}
\hline \multicolumn{2}{|c|}{$\begin{array}{c}\text { Staphylococci comparison with } \\
\text { other similar studies }\end{array}$} & \multicolumn{2}{c|}{$\begin{array}{c}\text { Escherichia coli comparison } \\
\text { with other similar studies }\end{array}$} \\
\hline My study & $34 \%$ & My study & $63.11 \%$ \\
\hline Bhatta et al., & $60 \%$ & Shrestha et al., & $80 \%$ \\
\hline Shrestha et al., & $41.31 \%$ & Payam et al., & $43.50 \%$ \\
\hline Garba et al., & $44 \%$ & & \\
\hline
\end{tabular}

Table.5 Comparison of my study with other studies in case of antibiotic resistance

\begin{tabular}{|l|r|l|r|}
\hline \multicolumn{2}{|c|}{$\begin{array}{c}\text { MRSA comparison with other } \\
\text { similar studies }\end{array}$} & \multicolumn{2}{c|}{$\begin{array}{c}\text { ESBL comparison with other } \\
\text { similar studies }\end{array}$} \\
\hline My study & $43.47 \%$ & My study & $52.35 \%$ \\
\hline Kshetry et al., & $37.60 \%$ & Michael et al., & $28 \%$ \\
\hline Subedi et al., & $15.40 \%$ & Pooja et al., & $91.70 \%$ \\
\hline Sanjana et al., & $39.60 \%$ & & \\
\hline Dibah et al., & $46.30 \%$ & & \\
\hline Tiwari et al., & $69.10 \%$ & & \\
\hline
\end{tabular}


Chart.1 Bacteriological profile of pathogen isolated

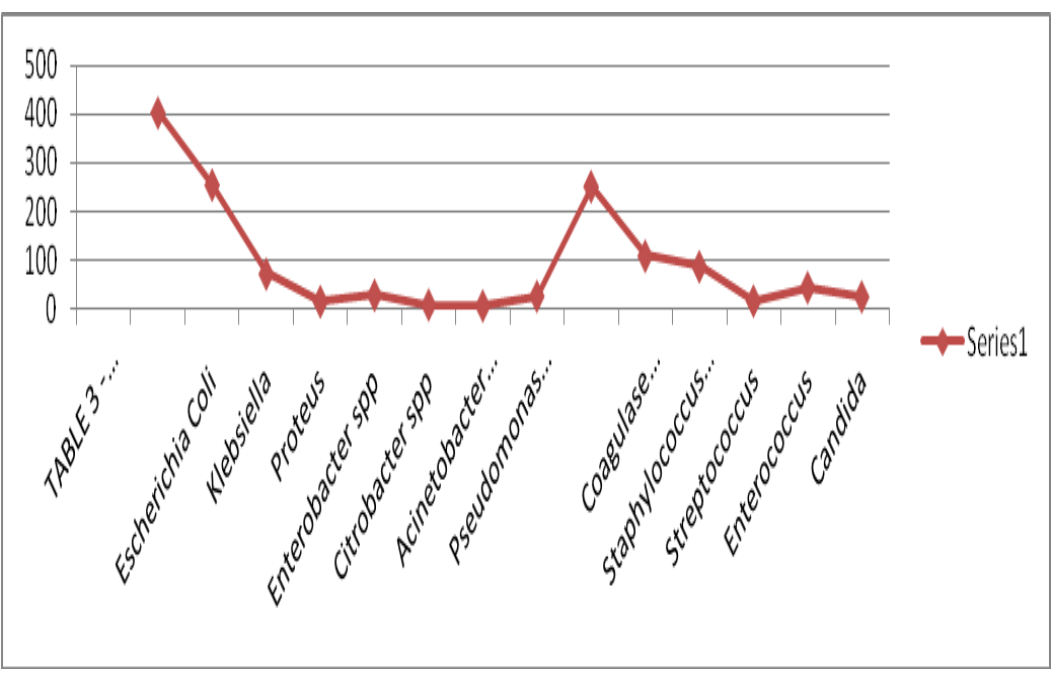

Chart.2 Antibiotic sensitivity pattern GNB

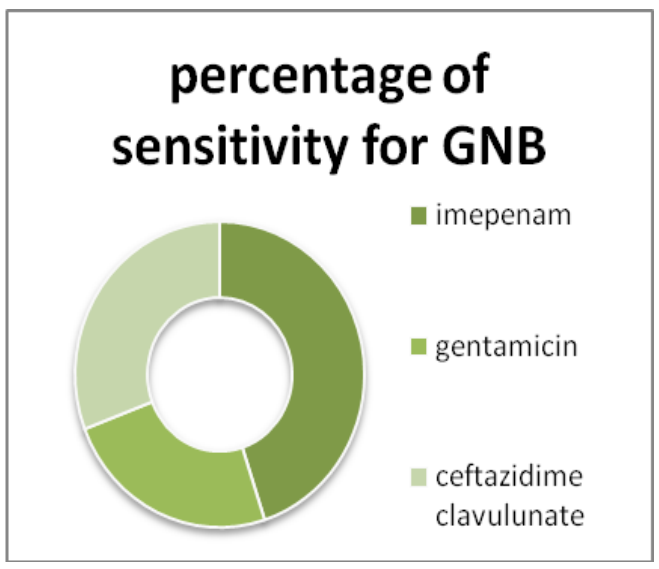

Chart.3 Antibiotic sensitivity pattern GPC

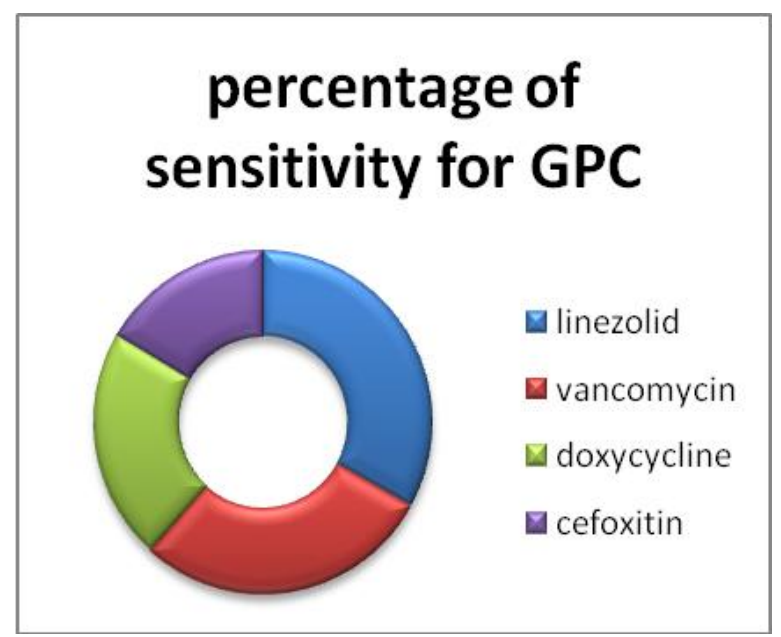


Chart.4 Superbug isolated from hospital settings

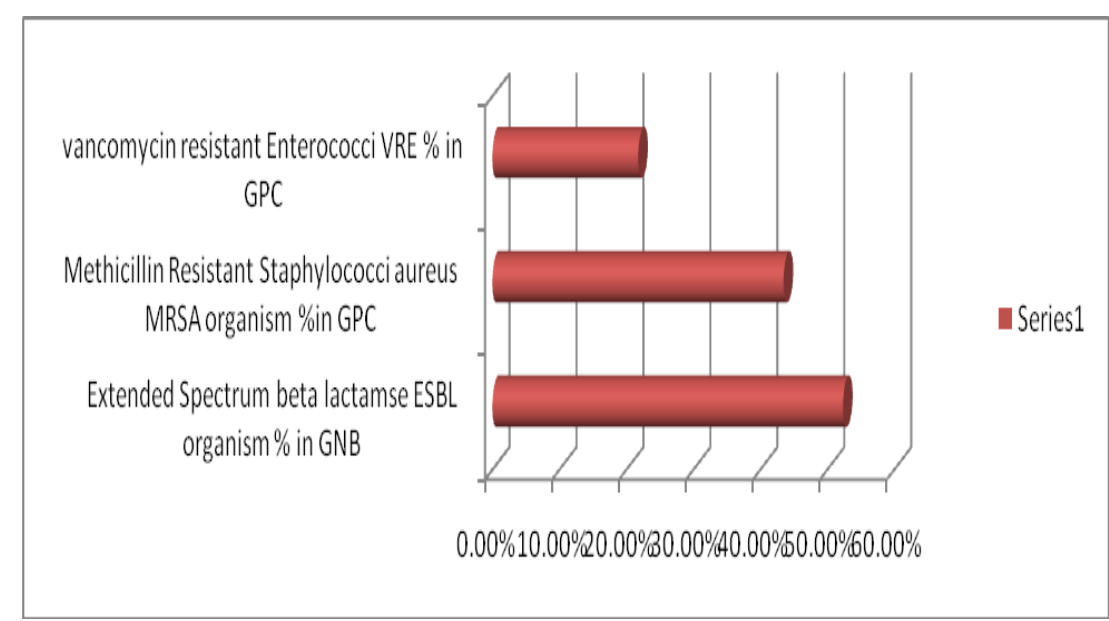

Antibiotic susceptibility patterns of gramnegative bacilli

Highest rate of susceptibility was seen toward Imipenam (87.6\%), followed by Ceftazidime clavulunate $(60 \%)$ gentamicin $(47 \%)$ (Table 2). The ESBL strain detected in $52.35 \%$ detected by noting the zone difference $\mathrm{b} / \mathrm{w}$ Ceftazidime and Ceftazidime clavulunate more than $5 \mathrm{~mm}$ (Table 3 ).

Infection is one of the most common and serious complications among the hospital acquired infection. It increases the length of hospital stay and accounts for the mortality rate up to $70-80 \%(12,13)$. The growth positivity reported by Bhatta and Lakhey (60\%) was higher to our finding (14)

As in our study, Bhatta and Lakhey (14), Shrestha and Basnet (15), and Garba et al., (18) (Table 4) also reported the S. aureus to be the most prevalent bacteria isolated from the cases of wound infections. In hospital the sources of $S$. aureus may be the inanimate objects, health care workers, and other patients. Further, due to presence of the $S$. aureus as normal flora of human body, the endogenous infections are also possible. The relatively higher resistance of the bacteria isolated from the children to the commonly used antibiotics is a matter of great concern. The prevalence of MRSA reported in our study was in accordance with that reported by Subedi and Brahmadathan (15.4\%) (19). However, higher rates were reported by Kshetry et al., (37.6\%) (6), Sanjana et al., (39.6\%) (20), Dibah et al., (46.3\%) (21), and Tiwari et al., (69.1\%) (22) (Table 5). In a recent study from Nepal, Adhikari et al., also reported higher rate of MRSA in comparison to our study (23). The difference in the rates of isolation of MRSA in different studies might be due to the difference in the level of irrational use of antibiotic, level of hygiene maintained in different hospitals, and effective implementation of hand hygiene program. But the high rate of isolation of MRSA from the children indicates a serious problem. The treatment of infection caused by MRSA may require the use of reserve drug, vancomycin. The use of vancomycin in children may cause the emergence of the vancomycin-resistant Gram positive bacteria, leaving little or no option for the treatment of serious infections caused by those superbugs.

In my study the predominant gram negative bacterial infection is of Escherichia coli which is in common with Payam Behzadi et al., (24) and Shrestha et al., (15) (Table 4). 
The ESBL strain common causing infection found was in correspondence with Pooja Shakya et al., (25) and Michael Osthoff et al., (26) (Table 5). Due to irrational use of antibiotics the drug resistant organism is emerging which is directly causing infection in people.

\section{Limitations of the study}

Because of resource constraints, we were unable to use molecular level analysis to confirm our results. Further, multicenter study including larger numbers of samples would have generated more significant results.

In conclusion, this study showed that E. coli and Coagulase Negative Staphylococci isolates were the predominant pathogens isolated at the Jaipuriya settings Sensitivity of Linezolid, Vancomycin, Doxycyline, Imipenam, Gentamicin, Ceftazidime clavulunate is seen in the bacterial strain is maximum. Since drug resistance is an evolving process, routine surveillance and monitoring studies should be conducted to provide physicians the updated and most effective empirical treatment.

\section{Recommendations}

1) Hand washing and proper sterilization techniques along with personal protective measures should be taken.

2) Culturing of sample should be sent before giving antibiotics as may give false negative results.

3) Pathogens should be identified and proper antibiotics should be give

\section{Abbreviation}

CLSI: Clinical and Laboratory Standards Institute

ATCC: American Type Culture Collection

MRSA: Methicillin-resistant Staphylococcus aureus

MIC: Minimum inhibitory concentration.

\section{References}

1. Shriyan, P., V. Prabhu, K. S. Aithal, U. N. Yadav, and M. J. Orgochukwu, "Profile of unintentional injury among under-five children in coastal Karnataka, India: a cross-sectional study," International Journal of Medical Science and Public Health, vol. 3, no. 11, pp. 1317-1319, 2014.

2 Peden, . M., K. Oyegbite, J. Ozanne-Smith et al., "World report on child injury prevention," Tech. Rep. 232, World Health Organization, 2008.

3. Mordi, R.M., and M. I. Momoh, "Incidence of Proteus species in wound infections and their sensitivity pattern in the University of Benin Teaching Hospital," African Journal of Biotechnology, vol. 8, no. 5, pp. 725-730, 2009.

4. Khanal, L.K., and B. K. Jha, "Prevalence of methicillin resistant Staphylococcus aureus (MRSA) among skin infection cases at a hospital in Chitwan, Nepal," Nepal Medical College Journal, vol. 12, no. 4, pp. 224-228, 2010.

5. Sdougkos, G., V. Chini, D. A. Papanastasiou et al., "Community associated Staphylococcus aureus infections and nasal carriage among children: molecular microbial data and clinical characteristics," Clinical Microbiology and Infection, vol. 14, no. 11, pp. 995-1001, 2008.

6. A. O. Kshetry, N. D. Pant, R. Bhandari et al., "Minimum inhibitory concentration of vancomycin to methicillin resistant Staphylococcus aureus isolated from different clinical samples at a tertiary care hospital in Nepal," Antimicrobial Resistance \& Infection Control, vol. 5, article no. 27, 2016.

7. M. Cheesbrough, District Laboratory 
Practice in Tropical Countries, Part II, Cambridge University Press, New York, NY, USA, 2nd edition, 2006.

8. J. G. Holt, N. R. Krieg, P. H. A. Sneath, J. T. Staley, and S. T. Williams, Bergey's Manual of Determinative Bacteriology, Williamsons and Wilkins, Baltimore, Md, USA, 1994.

9. Clinical and Laboratory Standards Institute, Performance Standards for Antimicrobial Susceptibility Testing: Twenty Second Informational Supplement, CLSI Document M100S22, CLSI, Wayne, Pa, USA, 2012.

10. J. M. Andrews, "Determination of minimum inhibitory concentrations," Journal of Antimicrobial Chemotherapy, vol. 48, supplement 1, pp. 5-16, 2001.

11. E. S. Amadi, P. N. Uzoaru, I. Orji, A. A. Nwaziri, and I. R. Iroha, "Antibiotic resistance in clinical isolates of Pseudomonas aeruginosa in Enugu and Abakaliki, Nigeria," Internet Journal of Infectious Diseases, vol. 7, no. 1, pp. 201-210, 2009.

12. F. Gottrup, A. Melling, and D. A. Hollander, "An overview of surgical site infections: aetiology, incidence and risk factors," World Wide Wounds, vol. 5, no. 2, pp. 11-15, 2005.

13. A. P. R. Wilson, C. Gibbons, B. C. Reeves et al., "Surgical wound infection as a performance indicator: agreement of common definitions of wound infection in 4773 patients," British Medical Journal, vol. 329, no. 7468, pp. 720-723, 2004.

14. C. P. Bhatta and M. Lakhey, "The distribution of pathogens causing wound infection and their antibiotic susceptibility pattern," Journal of Nepal Health Research Council, vol. 5, no. 1, pp. 22-25, 2007.

15. B. Shrestha and R. B. Basnet, "Wound infection and antibiotic sensitivity pattern of bacterial isolates," Post-
Graduate Medical Journal of NAMS, vol. 9, no. 1, pp. 1-6, 2009.

16. L. Kai-Yang, X. Zhao-Fan, Z. Luo-Man et al., "Epidemiology of pediatric burns requiring hospitalization in China: a literature International Journal of Microbiology 5 review of retrospective studies," Pediatrics, vol. 122, no. 1, pp. 132-142, 2008.

17. A. Onen, M. K. C, iّgdem, M. F. Geyik et al., "Epidemiology and control of nosocomial infections in paediatric surgery," Journal of Hospital Infection, vol. 52, no. 3, pp. 166-170, 2002.

18. I. Garba, Y. H. Lusa, E. Bawa et al., "Antibiotics susceptibility pattern of Pseudomonas aeruginosa isolated from wounds in patients attending Ahmadu Bello University Teaching Hospital, Zaria, Nigeria," Nigerian Journal of Basic and Applied Sciences, vol. 20, no. 1, pp. 32-34, 2012.

19. S. Subedi and K. N. Brahmadathan, "Antimicrobial susceptibility patterns of clinical isolates of Staphylococcus aureus in Nepal," Clinical Microbiology and Infection, vol. 11, no. 3, pp. 235237, 2005.

20. R. Sanjana, R. Shah, N. Chaudhary, and Y. Singh, "Prevalence and antimicrobial susceptibility pattern of methicillinresistant Staphylococcus aureus (MRSA) in CMS-teaching hospital: a preliminary report," Journal of College of Medical Sciences- Nepal, vol. 6, no. 1, pp. 1-6, 2010.

21. S. Dibah, M. Arzanlou, E. Jannati, and R. Shapouri, "Prevalence and antimicrobial resistance pattern of methicillin resistant Staphylococcus aureus (MRSA) strains isolated from clinical specimens in Ardabil, Iran," Iranian Journal of Microbiology, vol. 6, no. 3, pp. 163168, 2014.

22. H. K. Tiwari, A. K. Das, D. Sapkota, K. Sivarajan, and V. K. Pahwa, 
"Methicillin resistant Staphylococcus aureus: prevalence and antibiogram in a tertiary care hospital in western Nepal," Journal of Infection in Developing Countries, vol. 3, no. 9, pp. 681-684, 2009.

23. R. Adhikari, N. D. Pant, S. Neupane et al., "Detection of methicillin resistant Staphylococcus aureus and determination of minimum inhibitory concentration of vancomycin for Staphylococcus aureus isolated from pus/wound swab samples of the patients attending a tertiary care Hospital in Kathmandu, Nepal," Canadian Journal of Infectious Diseases and Medical Microbiology, vol. 2017, Article ID 2191532, 6 pages, 2017.

24. Payam Behzadi, Elham Behzadi, Hodjjat Yazdanbod, Mscb et al., A survey on urinary tract infections associated with the three most common uropathogenic bacteria, Medica- journal of clinical medicine, Volume 5 No.2 2010

25. Pooja Shakya, Dhiraj Shrestha, et al.,, ESBL production among E. coli and Klebsiella spp. causing urinary tract infection: A hospital based study, The Open Microbiology Journal, 2017, 11, 23-30

26. Michael Osth off A.B, Sarah L. Mc Guinness A et al., Urinary tract infections due to extended-spectrum beta-lactamase- producing Gramnegative bacteria: identification of risk factors and outcome predictors in an Australian tertiary referral hospital, International Journal of Infectious Diseases 34(2015): 79-83.

\section{How to cite this article:}

Bhagwati Chundawat, Manuja Agarwal, Nilofer Khayyam, Gaurav Dalela, Ekadeshi Sabhrawal and Vijeta Sharma. 2019. Bacteriological Profile and Antimicrobial Susceptibility Patterns of Bacteria Isolated from various Culture Samples of Patients Attending RDBP Jaipuriya Hospital, Jaipur. Int.J.Curr.Microbiol.App.Sci. 8(06): 727-735.

doi: https://doi.org/10.20546/ijcmas.2019.806.086 